\title{
Hidden weapons of microbial destruction in plant genomes John M Manners
}

\author{
Address: CSIRO Plant Industry, Queensland Bioscience Precinct, Carmody Road, St Lucia, Brisbane 4067, Australia.
} Email: John.Manners@csiro.au

Published: 26 September 2007

Genome Biology 2007, 8:225 (doi:10.1 186/gb-2007-8-9-225)

The electronic version of this article is the complete one and can be found online at http://genomebiology.com/2007/8/9/225

(C) 2007 BioMed Central Ltd

\begin{abstract}
Recent bioinformatic analyses of sequenced plant genomes reveal a previously unrecognized abundance of genes encoding antimicrobial cysteine-rich peptides, representing a formidable and dynamic defense arsenal against plant pests and pathogens.
\end{abstract}

Higher plants are sedentary and lack the adaptive immune system that many animals deploy when challenged by microbial pathogens. Nevertheless, plants are not defenseless, and have developed a variety of mechanisms to protect themselves against microbial attack. These include the production of proteins, secondary metabolites and reactive oxygen species that can inhibit the growth of microbial pathogens, the establishment of structural barriers such as lignin and polysaccharides that prevent penetration and colonization, and hypersensitivity responses that result in programmed cell death and isolate invading pathogens from sources of nutrients.

The defensive antimicrobial proteins produced by plants fall into two broad groups based on size. Examples of large antimicrobial proteins (more than 100 amino acid residues) are the chitinases and glucanases that are induced in plant tissues by fungal attack. These digest fungal cell-wall polymers and can inhibit and ultimately lyse fungal cells [1]. Plants also produce a diverse array of smaller proteins (less than 100 amino acid residues), most of which are cysteine-rich peptides (CRPs) that inhibit bacterial and fungal growth in vitro [2]. Many forms of CRPs occur in nature and are believed to comprise an important part of the innate immunity of both plants [3] and animals [4]. In plant tissues, CRPs are produced either constitutively, for example in seeds and reproductive tissues [3], where they can provide a constant defensive role, or can be induced at the site of challenge by a microbial pathogen and subsequently systemically in distal, non-challenged tissues [5]. The best-studied defensive role of CRPs is their ability to inhibit microbial growth in vitro, but many CRPs are inducible by wounding and have defensive roles against chewing insect pests [3,6]. The molecular details of the mode of action of many plant CRPs are unresolved, but one class, the plant defensins, are believed to act through interactions with specific components of the surface membranes of fungal pathogens $[2,7]$.

The diversity of antimicrobial CRPs has been determined in the past primarily from biochemically based 'biomining' projects where antimicrobial peptides are purified from plant extracts, novel peptide sequences identified and their genes subsequently cloned. More recently, the availability of complete genome sequences has enabled new bioinformatics-based approaches to the discovery of CRPs. Using this approach, Silverstein et al. [8,9] have now revealed that individual plant genomes encode a surprising abundance of genes for CRPs and that these molecules have an astonishing potential for functional specialization.

Classes of antimicrobial CRPs can be defined by their cysteine-spacing signatures and some examples are presented in Table 1. Within each class there is considerable diversity; for example, for the cyclotides it has been estimated that more than 9,000 variants exist in the plant family Violaceae alone [10]. There is also considerable variation in the processing and subcellular targeting of CRPs. Some, such as the defensins, are produced from relatively small preproteins and targeted to the endomembrane system, the apoplast (which comprises the cell walls collectively, a space in which small molecules can diffuse freely throughout the tissue), and in some cases the vacuole, by short amino-terminal and/or carboxy-terminal signal motifs [3]. Others (for example, Ib-AMP1 from Impatiens and 
Table I

Examples of antimicrobial CRPs from plants

\begin{tabular}{|c|c|c|c|c|c|}
\hline Class & Example & Plant species & Amino acids & Cysteine-spacing motif* & References \\
\hline Plant defensin & Rs-AFP2 & Raphanus sativus (radish) & 51 & $\mathrm{Cl}+5 \mathrm{C} 3 \mathrm{C} 9 \mathrm{C} 8 \mathrm{CIC} 3 \mathrm{C}$ & {$[14]$} \\
\hline Lipid-transfer protein & Ace-AMPI & Allium cepa (onion) & 93 & $\mathrm{C} 9 \mathrm{CI} 2 \mathrm{CC} 18 \mathrm{CIC} 23 \mathrm{CI} 5 \mathrm{C}$ & {$[15]$} \\
\hline Thionin & $\alpha$-Hordothionin & Hordeum vulgare (barley) & 45 & $\mathrm{CC} 7 \mathrm{C} 3 \mathrm{C} 8 \mathrm{C} 3 \mathrm{CIC7C}$ & [16] \\
\hline$\beta$-Barrelin & MiAMPI & Macadamia integrifolia & 76 & $\mathrm{C} 9 \mathrm{CIC} 25 \mathrm{CI} 4 \mathrm{CIIC}$ & {$[17,18]$} \\
\hline Snakin & StSNI & Solanum tuberosum (potato) & 63 & $\mathrm{C} 3 \mathrm{C} 3 \mathrm{C} 8 \mathrm{C} 32 \mathrm{CC} 2 \mathrm{CICIICICI2C}$ & [19] \\
\hline Vicilin fragment & MiAMP2 & Macadamia integrifolia & 45 & $\mathrm{C} 3 \mathrm{Cl} 2 \mathrm{C} 3 \mathrm{C}$ & {$[\mathrm{II}]$} \\
\hline Chitin-binding peptide & Ac-AMP2 & Amaranthus caudatus & 30 & $\mathrm{C} 4 \mathrm{C} 4 \mathrm{CC} 5 \mathrm{C} 6 \mathrm{C}$ & {$[20]$} \\
\hline Knottin-like & Mj-AMPI & Mirabilis jalapa & 36 & $\mathrm{C} 6 \mathrm{C} 8 \mathrm{CC} 3 \mathrm{CIOC}$ & {$[21]$} \\
\hline Cyclotide & Kalata BI & Oldenlandia affinis & 29 & $\mathrm{C} 3 \mathrm{C} 4 \mathrm{C} 4 \mathrm{CIC} 4 \mathrm{C} 6$ & {$[10]$} \\
\hline Impatiens & Ib-AMPI & Impatiens balsamina & 20 & CС $8 \mathrm{C} 3 \mathrm{C}$ & {$[12]$} \\
\hline
\end{tabular}

*Numbers refer to amino acid residues between cysteines $(C)$ in the polypeptide backbone.

MiAMP2 from Macadamia) exist in repeated units in very large precursor proteins and are released by proteolytic processing at multiple sites $[11,12]$.

In their most recent paper, Silverstein et al. [8] developed new search models for CRP sequences in plant genomes based on iterative queries for CRP motifs. They initially identified sequences of selected secreted CRPs that are synthesized with simple amino-terminal signal sequences in the preprotein. These classes include defensins, thionins and rapid alkanization factors (RALFs), the last group constituting CRPs with putative roles in development. Silverstein et al. [8] also identified novel founder sequences for hypothetical secreted CRP-encoding genes in the genome that had cysteine-spacing signatures not previously identified in purified CRPs. These sequence compilations were then used in iterative searches to identify related sequences until all matches were exhausted [8]. Initial searches across 4.8 million expressed sequence tags (ESTs) from 33 plant species identified approximately 146,000 matches representing 12,824 distinct CRPs, underscoring the massive genetic diversity of CRPs present in plants in nature.

In particular, the bioinformatics approach adopted by Silverstein et al. makes possible an assessment of the abundance and spectrum of CRP-encoding genes in individual plant genomes. In the Arabidopsis genome, 825 CRPs have now been identified [8,9]. Of these, 687 were related in sequence to known antimicrobial CRPs such as defensins, lipid-transfer proteins, thionins and chitin-binding proteins, suggesting that plants have an enormous potential arsenal of defense-related peptides encoded in their genomes. The rice genome appeared to contain 598 CRPs [8], slightly fewer than in Arabidopsis but still a considerable number of potential defense-related genes. Many of the identified CRPs had not been annotated previously and an important conclusion from these studies is that genome-annotation groups should pay particular attention to refining the calling procedures for genes encoding small proteins.

\section{Functional significance of multiple CRPs in plant genomes}

Functional redundancy appears to be an important feature of plant defense mechanisms and multiple antimicrobial proteins and metabolites are produced by plants in response to pathogen challenge. This redundancy presumably protects against selection for pathogen mutants for increased tolerance to any particular defense molecule. Studies of the mode of action of antimicrobial CRPs have revealed that fungi can rapidly develop tolerance to specific CRPs in vitro $[7,13]$. Even within classes of CRPs where there is similar cysteine spacing and a common structural framework there is variation in modes of action between members, presumably imparted by the more variable amino acid residues exposed on the protein surface. For example, the plant defensin subclass that includes RsAFP1 from radish and the subclass including DmAMP1 from dahlia appear to have different molecular modes of action against fungi [7] and require distinct membrane components in the targeted fungi for their toxicity. It is therefore possible that the mass of CRPs in plant genomes ensures functional diversity and provides a defense system that is durable in the face of highly adaptive pathogen populations.

One of the drawbacks of the genome-mining approach to CRP discovery compared with the biochemical approach is the uncertainty over whether an identified CRP-encoding gene sequence is expressed and functional, whether in plant defense or any other aspect of plant development. Silverstein et al. [8] investigated this in Arabidopsis by testing for the mRNAs of the newly identified CRP sequences using cDNA 
synthesis, amplification and sequencing, and showed that $61 \%$ of the tested genes appeared to be transcribed under the growth conditions studied. Further analysis using the massively parallel signature sequencing databases for Arabidopsis also revealed that a large proportion (12-22\% depending on the tissue) of the newly identified CRPs were expressed, primarily in the transcript pools from flowers and seeds. Similarly, an analysis of more than 4 million plant ESTs corresponding to CRPs showed that the largest proportion was from tissue libraries corresponding to reproductive organs such as flowers and seeds. Many plant defense molecules that are induced in vegetative tissues are expressed constitutively in inflorescences, presumably because this is such a critical stage of the plant life cycle and requires constant protection. Future work on the functional significance of CRPs in plants will most probably require a proteomics approach focused on the peptide size classes. It will be of particular interest to study the expression of the newly identified CRP genes and proteins in Arabidopsis tissues following pathogen challenge to better identify candidates for roles in plant defense.

Although most of this discussion has focused on the antimicrobial properties of CRPs and their role in defense, many CRPs have other functions, including regulatory roles in reproduction and development, with the RALF-like CRPs as examples. Dissecting out the physiological roles of the new array of CRPs will not be easy, as redundancy has generally thwarted attempts to use the insertional mutant libraries of Arabidopsis to implicate CRP genes in specific physiological processes. In vitro functions, such as antimicrobial activity, may be assigned by production of recombinant proteins from the gene sequences, but given the large number and diversity of CRP genes now identified in plant genomes this will require the development of new high-throughput peptide production and analysis systems.

\section{Evolution of CRP genes}

Many CRPs appear to be unevenly distributed across the plant kingdom. For example, the highly diverse cyclotides have only been found in the Rubiaceae and the Violaceae [10]. It is evident that some CRP sequences may have multiplied in particular plant genomes, whereas other CRP sequences have been lost. The comparison of CRP sequences in the rice and Arabidopsis genomes made by Silverstein et al. [8] illustrates this point very effectively. For example, defensin-like sequences are the most abundant CRP sequences in the Arabidopsis genome, with 323 members, whereas only 93 defensin-like genes are present in rice. In contrast, the rice genome has 13 CRP sequences for Bowman-Birk protease inhibitor CRPs, whereas these sequences are missing from the Arabidopsis genome.

The new genome-wide analyses provide some clues as to how CRP genes may evolve. Firstly, many CRP sequences are clustered in the genome and, therefore, can evolve rapidly through unequal homologous recombination. Analysis of several groups of CRP genes, such as the defensin-like genes in Arabidopsis and the seed prolamin genes in rice, indicates that such recombination can give rise to new cysteine signatures and, presumably, to new peptide backbone structures through altered folding. Silverstein et al. [8] also describe several fusions of CRPs with sequences of other CRPs or other proteins, including fusions to proline- and glycine-rich cell-wall proteins. These fusions may have been selected for because they anchor and concentrate antimicrobial CRPs at sites of microbial attack on the cell surface. Other novel fusions were observed, for example with defensin-like and thionin-like CRP sequences, and these could permit novel toxic activities combining diverse modes of action. Although one can only speculate on the functional significance of these fusions at present, the processes that give rise to such rearrangements provide considerable plasticity for the continued evolution of new CRP sequences and functions. In the case of plant-microbe interactions there is obviously considerable adaptive potential in plants for the development and selection of altered repertoires of CRP molecules with roles in plant defense.

In summary, genome-wide analysis of CRP genes has revealed an unexpected potential abundance and diversity of these molecules. CRPs have well established functional roles in plant defense and critical roles in controlling plant development are also emerging. The arrangement of CRP sequences in plant genomes suggests that they have high adaptive potential and are evolutionarily dynamic. The challenge for the future is to understand whether these molecules have a broader array of functions than has been described so far, and whether the large array of CRP genes present in plant genomes has evolutionary significance in plant phenotypic specialization.

\section{References}

I. Ferreira RB, Monteiro S, Freitas R, Santos CN, Chen Z, Batista LM, Duarte J, Borges A, Teixeira AR: The role of plant defence proteins in fungal pathogenesis. Mol Plant Pathol 2007, 8:677-700.

2. Broekaert WF, Cammue BPA, DeBolle MFC, Thevissen K, DeSamblanx GW, Osborn RW: Antimicrobial peptides from plants. Crit Rev Plant Sci 1997, I 6:297-323.

3. Lay FT, Anderson MA: Defensins - components of the innate immune system in plants. Curr Prot Pept Sci 2005, 6:85-101.

4. Lehrer RI: Primate defensins. Nat Rev Microbiol 2004, 2:727-738.

5. Manners JM, Penninckx IAMA, Vermaere K, Kazan K, Brown RL, Morgan A, Maclean DJ, Curtis MD, Cammue BPA, Broekaert WF: The promoter of the plant defensin gene PDFI.2 from Arabidopsis is systemically activated by fungal pathogens and responds to methyl jasmonate but not to salicylic acid. Plant Mol Biol 1998, 38: I07|-1080.

6. Gruber CW, Cemazar M, Anderson MA, Craik DJ: Insecticidal plant cyclotides and related cystine knot proteins. Toxicon 2007, 49:56I-575.

7. Thevissen K, Warnecke DC, Francois IEJA, Takemoto JY, Ferket KKA, Meert EMK, Cammue BPA: Defensins from insects and plants interact with fungal glucosylceramides. J Biol Chem 2004, 279:3900-3905

8. Silverstein KA, Moskal WA, Wu HC, Underwood BA, Graham MA, Town CD, VandenBosch KA: Small cysteine-rich peptides 
resembling antimicrobial peptides have been underpredicted in plants. Plant J 2007, $51: 262-280$.

9. Silverstein KA, Graham MA, Paape TD, VandenBosch KA: Genome organisation of more than 300 defensin-like genes in Arabidopsis. Plant Physiol 2005, I38:600-6I0.

10. Simonsen SM, Sando L, Ireland DC, Colgrave ML, Bharathi R, Goransson U, Craik DJ: A continent of plant defense peptide diversity: cyclotides in Australian Hybanthus (Violaceae). Plant Cell 2005, 17:3 I76-3189.

II. Marcus JP, Green JL, Goulter KC, Manners JM: A family of antimicrobial peptides is produced by processing of a $7 \mathrm{~S}$ globulin protein in Macadamia integrifolia. Plant $J$ 1999, 19:699-710.

12. Tailor RH, Aclan DP, Attenborough S, Cammue BPA, Evans IJ, Osborn RW, Ray JA, Rees SB, Broekaert WF: A novel family of small cysteine-rich antimicrobial peptides from seed of Impatiens balsamina is derived from a single precursor protein. J Biol Chem 1997, 272:24480-24487.

13. Stephens C, Harrison SJ, Kazan K, Smith FWN, Goulter KC, Maclean $D J$, Manners JM: Altered fungal sensitivity to a plant antimicrobial peptide through over-expression of yeast cDNAs. Curr Genet 2005, 47:194-201.

14. Terras FRG, Schoofs HME, De Bolle MFC, Van Leuven F, Rees SB, Vanderleyden J, Cammue BPA, Broekaert WF: Analysis of two novel classes of plant antifungal proteins from radish (Raphanus sativus L.) seeds. J Biol Chem 1992, 267:I530I-I 5309.

15. Cammue BPA, Thevissen K, Hendriks M, Eggermont K, Goderis IJ, Proost P, Van Damme J, Osborn RW, Guerbette F, Kader JC, Broekaert WF: A potent antimicrobial protein from onion seeds showing sequence homology to plant lipid transfer proteins. Plant Physiol 1995, 109:445-455.

16. Ponz F, Paz-Ares J, Hernandez-Lucas C, Garcia-Olmedo F, Carbonero $P$ : Cloning and nucleotide sequence of a cDNA encoding the precursor of the barley toxin $\alpha$-hordothionin. Eur J Biochem 1986, I 56:131-135.

17. Marcus JP, Goulter KC, Green JL, Harrison SJ, Manners JM: Purification, characterization and cDNA cloning of an antimicrobial peptide from Macadamia integrifolia. Eur J Biochem 1997, 244:743-749.

18. McManus AM, Nielsen KJ, Marcus JP, Harrison SJ, Green JL, Manners JM, Craik DJ: MiAMP I, a novel protein from Macadamia integrifolia adopts a greek key $\beta$-barrrel fold unique amongst plant antimicrobial proteins. J Mol Biol 1999, 293:629-638.

19. Berrocal-Lobo M, Segura A, Moreno M, Lopez G, Garcia-Olmedo F, Molina A: Snakin-2, an antimicrobial peptide from potato whose gene is locally induced by wounding and responds to pathogen infection. Plant Physiol 2002, I 28:951-96I.

20. Broekaert WF, Marien W, Terras FR, De Bolle MF, Proost P, Van Damme J, Dillen L, Claeys M, Rees SB, Vanderleyden J, Cammue BPA: Antimicrobial peptides from Amaranthus caudatus seeds with sequence homology to the cysteine/glycine-rich domain of chitin-binding proteins. Biochemistry 1992, 31:4308$43 \mid 4$.

21. Cammue BP, De Bolle MF, Terras FR, Proost P, Van Damme J, Rees $\mathrm{SB}$, Vanderleyden J, Broekaert WF: Isolation and characterization of a novel class of plant antimicrobial peptides from Mirabilis jalapa L. seeds. J Biol Chem 1992, 267:2228-2233. 